Japanese Journal of Physiology, 32, 971-981, 1982

\title{
Effects of Sweat Gland Training by Repeated Local Heating
}

\author{
Tokuo Ogawa, Masami Asayama, and Toshiaki Miyagawa \\ Department of Physiology, Aichi Medical University, \\ Aichi, 480-11 Japan
}

\begin{abstract}
Effects of sweat gland training by daily local heating were examined and its significance in heat acclimatization was evaluated. Training by 2-hr immersion of an arm in hot water of $43^{\circ} \mathrm{C}$ caused distinct augmentation of sweat gland activity in the trained area, with reduction in the degree of hidromeiosis, when tested by an arm bag collection of sweat. Concentrations of sweat electrolytes also showed definite decreases. The general tendency that $\mathrm{Na}$ and $\mathrm{Cl}$ concentrations in sweat rise in the course of hidromeiosis was attenuated or even reversed after the training. The sweat test using resistance hygrometry failed to show a marked or consistent increase in sweat rate of the trained area, although an increase was the common case on the dorsum of the hand and the extensor aspect of the forearm. The effect of training appeared in a few days of training, developed progressively with training days and showed a tendency to develop even after 3 weeks of training. The same training in midsummer failed to exert significant effects on sweat gland activity, suggesting that the sweat gland had been naturally trained to a considerable degree by then. On the other hand, training by repeated radiant heating of a local area caused only obscure changes in the activity of sweat glands. The present results reveal that sweat glands can be trained to be resistant to hidromeiosis in a hot-humid environment and that such peripheral changes appear to play a predominant role in augmentation of sweating capacity in the early stage of heat acclimatization. Key Words: sweating, sweat gland training, heat acclimatization, hidromeiosis, sweat electrolytes.
\end{abstract}

It has been generally recognized that the increased sweat response to heat load in association with heat acclimatization is due to both adaptive changes in the central thermoregulatory activity and increased secretory capacity of sweat glands, the latter of which has been considered to play a predominant role (Fox et al., 1964; CHEN and Elizondo, 1974). In our previous study (OGAwA and ASAYAMA, 1978), it was demonstrated that the potentiation of the secretory capacity of sweat glands precedes the more gradual changes in the activity of the central

Received for publication April 1, 1982

小川德雄, 朝山正己, 宮側敏明 
sudomotor mechanism in the course of experimental heat acclimation. Indeed, local sweat glands can be "trained" readily by daily repetition of various local stimulations, such as hot air blowing to a local area (KUNO, 1956), hot water immersion of one arm (Fox et al., 1964), and local administration of a cholinergic agent (Collins et al., 1966). Contrarily, the sweat increment is prevented in the arm kept cool locally during experimental heat acclimation (Fox et al., 1964; Chen and Elizondo, 1974), but not by local anesthesia by nerve block (CHEN and Elizondo, 1974). On the other hand, CHEN and Elizondo (1974) failed to observe a significant change in sweat response at the "trained" area to heat exposure. They maintain that peripheral modification of sweating capacity can occur only during heat acclimation by heat exposure of the whole body.

It should be clarified whether local sweat gland training mimics the peripheral changes associated with natural heat acclimatization. The present study was proposed to investigate the characteristics as well as the extent of the local training on sweat gland activity and to evaluate the role of the local changes in heat acclimatization. Effects of sweat gland training on hidromeiosis were examined with special concern.

\section{METHODS}

The subjects were healthy male students, aged 19 to 23 .

The experimental schedules involving sweat gland training are illustrated in Fig. 1. The procedure for sweat gland training in most series (Series 1 and 2) largely followed the one employed by Fox et al. (1964). The left upper extremity distal to just above the elbow was immersed in a stirred hot water bath of $43^{\circ} \mathrm{C}$ for $2 \mathrm{hr}$. This training procedure was repeated daily for 15 days in most of the cases and 21 days in a few. The skin temperature of the immersed arm was monitored at the cubital fossa and the dorsum of the hand during the training in a few cases. The thermistor tip was covered with the surrounding thin skin folds and held water-tight with small pieces of surgical tape. The measured value ranged between 40.5 and $41.0^{\circ} \mathrm{C}$.

In another series (Series 4), the left forearm and hand corresponding to the trained area in the above series was kept warmed for $2 \mathrm{hr}$ by radiant heat, instead of a hot water bath. The arm was held within the hollow of a specially-designed drum-shaped heater, the power of which was adjusted to keep the temperature of various skin areas of the warmed arm within the range of 40.5 to $42.0^{\circ} \mathrm{C}$. The procedure was also repeated for 15 consecutive days.

Environmental thermal condition during training was not strictly set but was temperate with light clothing. The training was done at about the same time every evening convenient to each subject.

No artificial training was imposed on sweat glands in Series 3, where sweat tests were carried out in midsummer. 


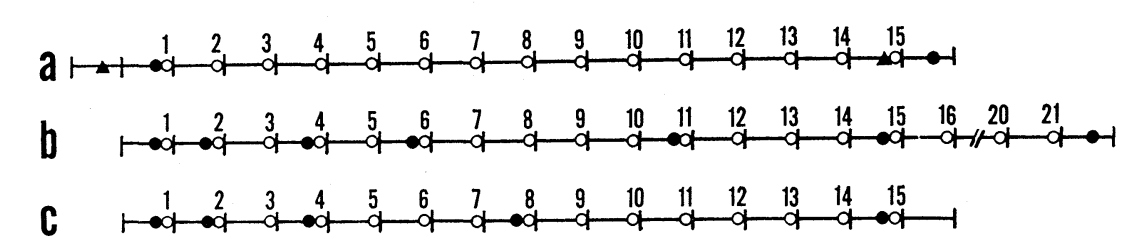

Fig. 1. Experimental schedules for Series 1(a), 2(b, c), and 4(a). O, training, with numerals indicating training days; $\Delta$, Test $\mathrm{A} ; \bullet$, Test $\mathrm{B}$.

Sweat tests were carried out between 2 and 7 p.m. as scheduled (Fig. 1). Two kinds of tests (Tests A and B) were done on separate days, and Test A was done one day prior to the day for Test $\mathrm{B}$.

Test A was done using resistance hygrometry. Local sweat rates during exposure to heat were compared between symmetric areas of bilateral forearms and hands. The subject, wearing only short pants, sat in a climate chamber set at $40^{\circ} \mathrm{C}$ with r.h. of $40 \%$. The test started after approximately $1 \mathrm{hr}$ for thermal equilibrium. A plastic capsule covering $15 \mathrm{sq} \mathrm{cm}$ of a skin area was ventilated with air of a pre-set low humidity and the outlet humidity change was sensed by a hygrosensitive element whose electric resistance change was recorded on a penwriting oscillograph. Sweat rates on two pairs of symmetric test areas were recorded simultaneously and after some 10 minutes, test areas were switched to two other pairs. The mean sweat rate for each test area was obtained by planimetric measurement of the record, and the left-to-right ratio (L/R ratio) of the mean sweat rate was calculated for each pair of the symmetric test areas.

Test $\mathrm{B}$ was done using the arm bag method. The seminude subject assumed a sitting position at the room temperature of $30^{\circ} \mathrm{C}$ with r.h. of $40 \%$ for approximately $30 \mathrm{~min}$ and then immersed both legs into a stirred hot water bath of $43^{\circ} \mathrm{C}$. Each of both upper extremities distal to just above the elbow (to be simply called arm) was enclosed in an airtight vinyl bag and the sweat discharged within the bag was drained off through a stoppered outlet at the bottom every 20 min for a period of $120 \mathrm{~min}$.

Concentrations of sodium and potassium in sweat samples collected for each period of $40 \mathrm{~min}$ in Test B were determined by a flame photometer (Hitachi 205). Chloride concentrations of the sweat samples were also determined using a chloride meter (Joko Sangyo, C-50). Rectal temperature and skin temperatures of the test areas of the bilateral forearms were measured by thermistor thermometers in some experiments. Most of experiments were carried out between December and May (to be simply called winter), except for a part of Series 2 and 3.

\section{RESULTS}

Series 1: Effects of the 2-week training by hot water immersion

Test $\mathrm{A}$ failed to reveal definite effects of the sweat gland training. Changes

Vol. 32, No. 6, 1982 

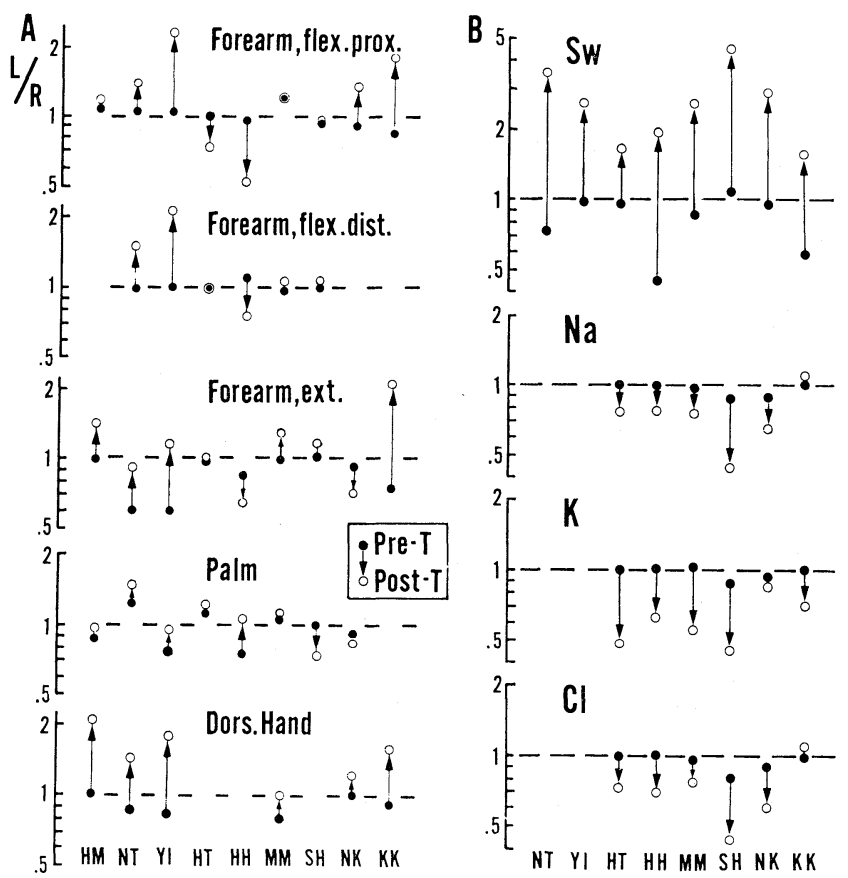

Fig. 2. Changes in $L / R$ ratio of sweat rates and of concentrations of sweat electrolytes by 2-week training of the left arm with hot water bath. A: sweat rates on various areas by Test A; B: total sweat amount by Test $\mathrm{B}$ and $\mathrm{Na}, \mathrm{K}$, and $\mathrm{Cl}$ concentrations in sweat.

in $\mathrm{L} / \mathrm{R}$ ratio of the mean sweat rate at various symmetric areas are illustrated for each of 9 subjects in Fig. 2A. Although the $\mathrm{L} / \mathrm{R}$ ratio increased in many areas after the training including all the areas in 5 subjects, it even decreased in some areas of 4 subjects. A consistent effect of the training was noted only in the dorsum of the hand, where the $L / R$ ratio was increased in all of the cases tested. The $L / R$ ratio in the extensor aspect of the forearm increased after the training in most of the cases. Considerable individual variations were noted in regional differences in changes of the $\mathrm{L} / \mathrm{R}$ ratio.

On the other hand, the effect of the local training was evident in Test B. Changes in the $\mathrm{L} / \mathrm{R}$ ratios of total sweat amount during the $120 \mathrm{~min}$ period and of mean electrolyte concentrations in sweat are illustrated in Fig. 2B. Before the training, sweat outlet was more or less greater in the right arm than in the left arm in a majority of the subjects. The effect of right or left handedness on sweating has been investigated in a separate series by our group (MrYAGAWA et al., 1981), which demonstrated that activities of sweat glands are generally higher in the arm of the dominant side than in the other arm, especially in right-handed individuals. In the present study, all of our subjects were right-handed. After the training of the left arm, sweat response in the left arm exceeded remarkably 

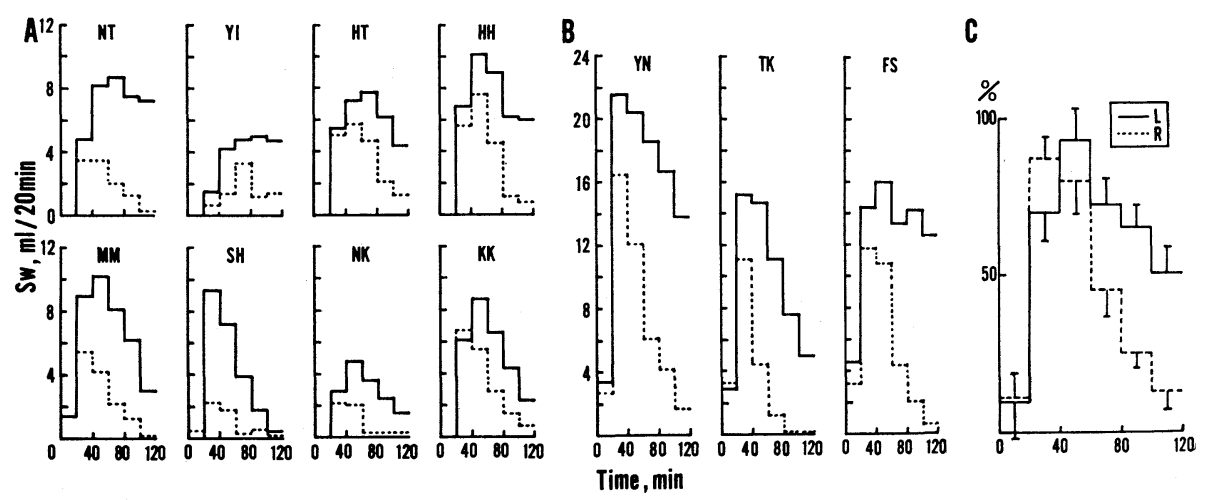

Fig. 3. Time course of sweat rates on the left and right arms measured by Test B after 2-week training of the left arm by hot water immersion. A: Series 1; B: winter experiments of Series 2; C: mean relative time course $( \pm$ S.E.) of sweat rate in the left and right arms. Data were taken from A and B as percent value of maximum sweat rate in each test area.

that in the right arm.

Changes in electrolyte concentrations in sweat were also noticeable. Definite decreases in concentrations of $\mathrm{Na}^{+}, \mathrm{K}^{+}$, and $\mathrm{Cl}^{-}$were noted in sweat from the left arm after its training, with exception of $\left[\mathrm{Na}^{+}\right]$and $\left[\mathrm{Cl}^{-}\right]$in subject $\mathrm{KK}$ which showed insignificant changes (Fig. 2B).

The most remarkable changes were noted in the time course of sweating in Test B. Sweat rate within the arm bag reached the maximum usually in 40 to 60 min of hot water immersion of both legs, followed by a rather rapid decline (hidromeiosis) before the training. In the left arm after the local training, the time to reach the maximum sweat rate was delayed in 6 out of the 8 subjects who underwent this test, and the subsequent decline in sweat rate was slowed down in all but one subject ( $\mathrm{SH})$, as compared with the time course of sweat rate in the untrained right arm (Fig. 3A). Such a general trend is more clearly demonstrated in Fig. 3C, where the time course of sweat rate is expressed as percent value of the maximum sweat rate for each data and averaged for 11 subjects (including data of Fig. 3B for Series 2). Differences in skin temperature between symmetric areas were minimal $\left(0-0.3^{\circ} \mathrm{C}\right)$ in all the cases.

The effect of sweat gland training on the time course of the electrolyte concentrations was also noticeable. Not only $\left[\mathrm{Na}^{+}\right],\left[\mathrm{K}^{+}\right]$, and $\left[\mathrm{Cl}^{-}\right]$were generally lowered after the training, but also the general tendency to increase in $\left[\mathrm{Na}^{+}\right]$and $\left[\mathrm{Cl}^{-}\right]$as hidromeiosis progressed, and turned to be obscure or even reversed in the sweat samples from the trained left arm (see Fig. 6 for the average time course). $\left[\mathrm{K}^{+}\right]$failed to show obvious changes during hidromeiosis before the training, whereas it showed a definite tendency to decline after the training. The $L / R$ 


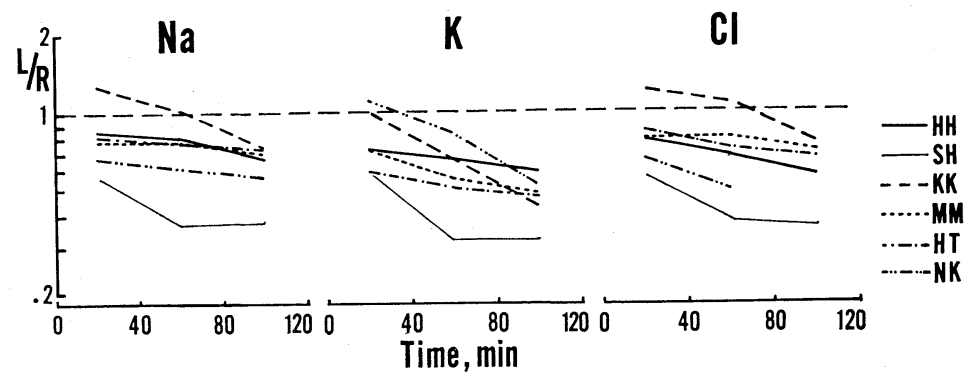

Fig. 4. Time course of $\mathrm{Na}^{+}, \mathrm{K}^{+}$, and $\mathrm{Cl}^{-}$concentrations in sweat collected in the arm bag by Test $\mathrm{B}$ after 2 -week training of the left arm by hot water immersion.

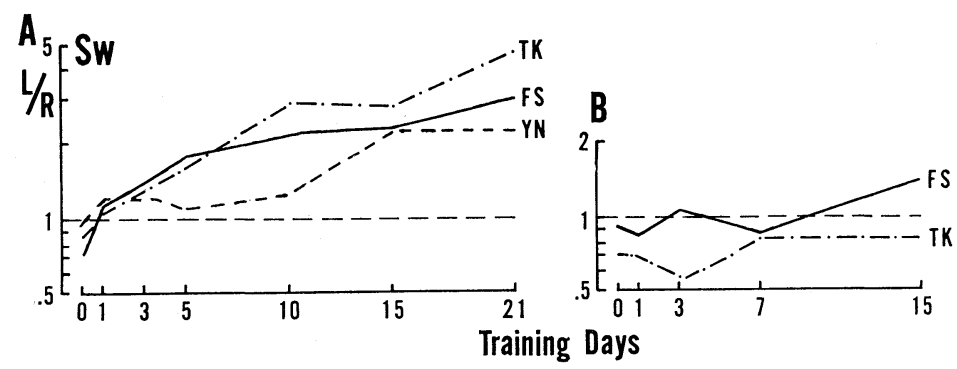

Fig. 5. Changes in $L / R$ ratio of total sweat amount measured by Test $B$ in the course of training of the left arm by hot water immersion. A: winter experiments with 21-day training; B: summer experiments with 15-day training.

ratios of $\left[\mathrm{Na}^{+}\right]$and $\left[\mathrm{Cl}^{-}\right]$as well as $\left[\mathrm{K}^{+}\right]$declined progressively, even in subject $\mathrm{KK}$, in whom $\left[\mathrm{Na}^{+}\right]$and $\left[\mathrm{Cl}^{-}\right]$exceptionally failed to decrease after the training (Fig. 4).

Series 2: Progress of the increase in sweating activity in the course of sweat gland training

This series consisted of winter experiments on 3 subjects and summer tests on 2 of those 3 subjects.

In the winter experiments, daily hot water bath of the left arm was continued for 21 days and Test B was carried out as scheduled (Fig. 1B). Changes in the $L / R$ ratio of total sweat amount during the 120 -min test period in the course of the training session are illustrated for each subject in Fig. 5A. The training effect on sweat rate was seen in a few days of training and increased with the training days. Even after the 21-day training, the trend appeared to be continuing. The data after the 15th day training are illustrated in Fig. 3B for comparison with those of Series 1 (Fig. 3A). Sweat response in this series were much greater than that in Series 1, even in the untrained right arm. This tendency was likely attributed to the development of heat acclimation to some degree due 
to repeated heat exposures for the frequent sweat test, though not on consecutive days. The least rise in the $L / R$ ratio was noted in subject $Y N$, the only active athlete among our subjects, in whom a considerable increase in sweat rate was noted also in the untrained right arm where the sweat rate nearly doubled the value of the pretrained test $(\times 1.9)$. No obvious changes in the $L / R$ ratio of $\left[\mathrm{Na}^{+}\right]$or $\left[\mathrm{Cl}^{-}\right]$were noted after the training in this series.

In the summer experiments, the daily hot bath of the left arm was continued for 15 days and Test B was done as scheduled (Fig. 1C). As shown in Fig. 5B, the local training in midsummer apparently exerted minimum effects, and no substantial increase in the $L / R$ ratio of sweat amount was noted in the course of the training, except for the data after the 15-day treatment in subject FS, where the mild increase $(\times 1.4)$ in the $L / R$ ratio after the training was attributed to a diminution of the degree of hidromeiosis in the trained arm. No obvious or consistent changes in concentrations of sweat electrolytes were noted in the trained arm.

Series 3: Comparison of effects on sweating of sweat gland training with those of natural heat acclimatization

Test B was done in August on 7 subjects who had undergone the experiments of sweat gland training by hot water bath in winter, and the results of the winter and summer tests were compared with each other. The results are summarized in Fig. 6. The magnitude of sweat response in natural acclimatization was variable, compared with increased response after the local training. The reduced tendency for hidromeiosis was also seen in the naturally acclimatized subjects. The electrolyte concentrations in the summer sweat were even lower than those in the sweat from the arm trained locally in winter, while time courses of their values were not so characteristic as those in the trained arm.

Series 4: Effects of the 2-week training by radiant heating

Results obtained by Test A were similar to those in Series 1, but the changes
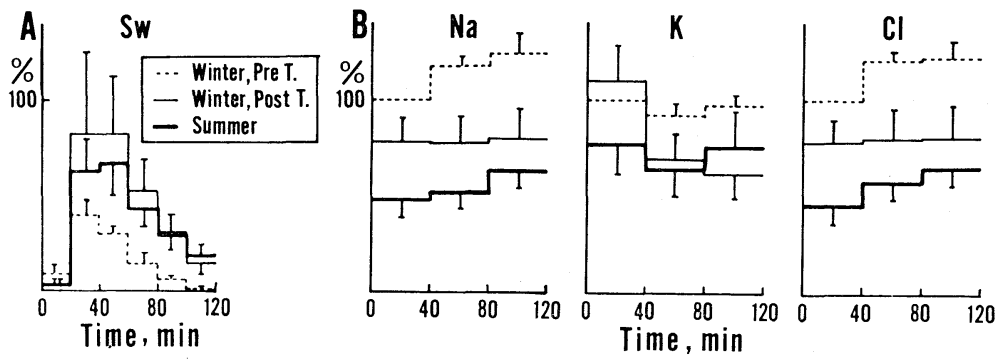

Fig. 6. Mean relative time course ( \pm S.E.) of (A) sweat rate, and (B) $\left[\mathrm{Na}^{+}\right],\left[\mathrm{K}^{+}\right]$, and $\left[\mathrm{Cl}^{-}\right]$ in sweat from the left arm of 7 subjects. Each data was calculated as percent value of total sweat amount in the pre-training test in winter in $\mathrm{A}$, and of the first 40 -min value in the pre-training test in winter in $\mathrm{B}$. 

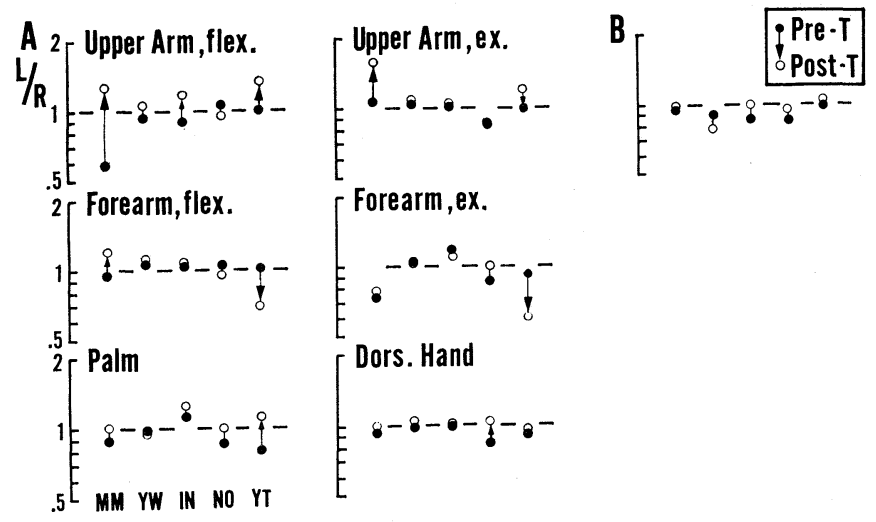

Fig. 7. Changes in $L / R$ ratio of sweat rates by 2 -week training of the left arm with radiant heat. A: sweat rates on various areas of the arm by Test A; B: total sweat amount by Test B.

were by far obscure (Fig. 7A). In this series, sweat rates in the flexor and extensor aspects of the upper arm were also tested and the $L / R$ ratio of them were increased in 4 out of 5 subjects. On the other hand, Test $B$ revealed little change in total sweat amount after the training by radiant heating (Fig. 7B). The appearance and the rate of decline in sweating were also similar to the pre-training data.

Throughout the above 4 series, the rectal temperature (Tre) increased more or less during the test. The degree of the increase $(\Delta T \mathrm{re})$ varied from test to test but no significant tendency was noted in $\Delta T$ re with the training days. However, the mean of $\Delta T$ re in the summer experiments $\left(0.38 \pm 0.21^{\circ} \mathrm{C} \mathrm{S}\right.$.D. $)$ was significantly less than that in the winter ones $\left(0.67 \pm 0.32^{\circ} \mathrm{C}\right.$ S.D.; $\left.p<0.05\right)$.

\section{DISCUSSION}

The results of the present study strongly suggest that sweat glands trained by repeated hot water immersion of a local area increase their sweat-secretory activity and this mimics changes in sweat gland activity in natural heat acclimatization. These results are in accord with those reported by Fox et al. $(1964,1967)$. CHEN et al. (1974) failed to observe the increased sweat output in the "locally trained" area when the subject was exposed to heat, but demonstrated that local cooling during heat acclimation prevented sweat increment, as was reported by Fox et al. (1964). Chen et al. concluded that increased sweating capacity following heat acclimation can be modified peripherally by local treatment during whole body heating. They criticised training in the studies of Fox et al. saying it was unphysiological because the skin was heated above $42^{\circ} \mathrm{C}$, where the heat would stimulate sweat glands directly. However, in the training by hot water bath in the study of Fox et al. as well as ours, it was the temperature of bathing water that 
was $43^{\circ} \mathrm{C}$ but not the skin temperature, which was $40.5-41^{\circ} \mathrm{C}$ according to our careful measurements. Although the room temperature was temperate, all the subjects experienced mild generalized sweating during training. Local heating within the physiological range is known to augment sweat gland activity (MACINTYRe et al., 1968; OGAWA, 1970).

The main differences in methods between the study of Chen et al. and that of Fox et al. lie in the methods of measurements of local sweat rate. In the former, the resistance-hygrometric measurement was done on sweat discharged from a skin area which was kept dry by ventilation with dry air, whereas in the latter, sweat was collected by draining off from an unventilated skin area where hidromeiosis took place. In the present study, sweat tests were carried out using both methods, which elucidated the discrepancies between the studies of those previous workers. In the sweat test using ventilated capsules, the effect of the training was generally obscure with considerable regional and individual variations, although the effect appeared to be consistent in the dorsum of the hand. Greater increment of sweat gland activity in the extremities than in the trunk during heat acclimation has been demonstrated by HöFLER (1968), and the present results suggest regional differences in susceptibility for the training within the upper extremity. There appears to be a tendency that sweat glands on the extensor aspect are trained more readily than those on the flexor aspect. On the other hand, the training effect was evident in the sweat test using the arm bag, in which sweat amount was remarkably increased with a reduced rate of decline in sweating. Differences in effects between experimental acclimation in hot-dry and in hot-wet conditions were investigated by Fox et al. (1967). Most prominent observations in their study were that the rate of decline in sweating was reduced in acclimation to hot-wet climate or more remarkably in the arm which had been exposed to hot-wet conditions during acclimation. Similar results were obtained in our local training experiments with wet heat (hot water immersion) and dry heat (radiant heating). It may be assumed that "resistance" to hidromeiotic process is an adaptive change and develops only in the skin area which has been kept wet during training by local heating, whereas local training with dry heat exerts little effect on sweat gland activity.

It is suggested from the results of Series 3 that the resistance to hidromeiosis may develop more readily by local training with wet heat than in natural heat acclimatization. This may be attributed to a higher degree of wetness of the local skin in the former.

Although the mechanism of hidromeiosis has been fully established, the hypothesis supported by many recent experimental studies is that hydration of the keratinized portion of the sweat duct narrows and finally mechanically occludes its orifice (SARGENT, 1962; KerSLAKe, 1972). If so, the explanation for the development of resistance to hidromeiosis by training with wet heat would be that repeated episodes of sweating with the presence of hidromeiosis causes some adap- 
tive changes, either morphological or functional, such as widening of the sweat duct orifice or increase in sweat-secretory pressure. Otherwise, it should be considered that hidromeiosis might involve functional changes of the sweat gland, which would be affected by sweat gland training.

Another noticeable observation made in the present study was that concentrations of sodium, potassium and chloride in sweat were reduced after the training with wet heat. It is a well-known fact that the concentration of those sweat electrolytes is a function of sweat rate: $\left[\mathrm{Na}^{+}\right]$and $\left[\mathrm{Cl}^{-}\right]$are known to be elevated as sweat rate increases, while $\left[\mathrm{K}^{+}\right]$tends to decrease. Those changes are attributed to increased amounts of the electrolytes which escape ductal transport with an increase of sweat flow in the duct and in part to a change in $\left[\mathrm{Na}^{+}\right]$and $\left[\mathrm{Cl}^{-}\right]$in plasma. During hidromeiosis, however, $\left[\mathrm{Na}^{+}\right]$and $\left[\mathrm{Cl}^{-}\right]$often increase as sweating declines (SARGENT, 1962). This phenomenon has been attributed by some investigators (e.g., BULMER and Forwell, 1956) to decreased ductal reabsorptive capacity of sodium concomitant with hidromeiosis. However, it may be more likely to assume that increased intraductal pressure due to ductal stenosis at the orifice interferes with osmosis of water following sodium secretion at the secretory coil. In the present study, concentrations of all the three electrolytes in sweat were reduced after the local training by hot bath while sweat output was increased, and further, the trend to increase in their concentrations during hidromeiosis was reduced, or even reversed in some cases. It has been well recognized that concentrations of sweat salts are reduced by heat acclimatization, as also shown in the present study as their seasonal differences. Those changes in sweat salts are generally attributed to increased capacity of ductal reabsorption of sodium chloride due to increased secretion of aldosterone, and participation of any local factors has been disputed (KUNO, 1956). However, the present results reveal that local changes in sweat secretory process take a part in modifying concentrations of sweat electrolytes, at least in the presence of hidromeiosis. Exceptionally, little changes were noted in the $\mathrm{L} / \mathrm{R}$ ratio of $\left[\mathrm{Na}^{+}\right]$and $\left[\mathrm{Cl}^{-}\right]$even after a 21-day training in Series 2, where sweat amount was profuse in the trained arm and this may account for the increase in sweat electrolyte concentrations masking the effect of training to reduce them.

The effect of local training appears to develop readily as was shown in Series 2 , where an increase in the $L / R$ ratio of sweat rate was noted as early as within a few days of training. This observation is in accord with the results of our previous study, where evidence was provided that increase in secretory capacity of sweat glands appears in a relatively early stage of experimental heat acclimation (OgAwa and Asayama, 1978). Furthermore, although cases were limited, the results of Series 2 suggest that local changes in sweat gland activity have progressed considerably in the course of natural heat acclimatization by midsummer. Local training in August failed to cause substantial changes in sweat gland activity.

This work was supported in part by a Grant-in-Aid for Scientific Research from the Ministry 
of Education, Sciences and Culture of Japan (No. 00437005).

\section{REFERENCES}

Bulmer, M. G. and Forwell, G. D. (1956) The concentration of sodium in thermal sweat. J. Physiol. (Lond.), 132: 115-122.

Chen, W. Y. and Elizondo, R. S. (1974) Peripheral modification of thermoregulatory function during heat acclimation. J. Appl. Physiol., 37: 367-373.

Collins, K. J., Crockford, W. G., and Weiner, J. S. (1966) The local training effect of secretory activity on the response of eccrine sweat glands. J. Physiol. (Lond.), 184: 203-214.

Fox, R. H., Goldsmith, R., Hampton, I. F. G., and Hunt, T. J. (1967) Heat acclimatization by controlled hyperthermia in hot-dry and hot-wet climates. J. Appl. Physiol., 22: 39-46.

Fox, R. H., Goldsmith, R., Hampton, I. F. G., and Lewis, H. E. (1964) The nature of the increase in sweating capacity produced by heat acclimatization. J. Physiol. (Lond.), 171: 368-376.

HÖFLER, W. (1968) Changes in regional distribution of sweating during acclimatization to heat. J. Appl. Physiol., 25: 503-506.

Kerslake, D. McK. (1972) The Stress of Hot Environments, Cambridge University Press, London, pp. 145-160.

Kuno, Y. (1956) Human Perspiration, C. C. Thomas, Springfield, pp. 318-335.

MacIntyre, B. A., Bullard, R. W., Banerjee, M. R., and Elizondo, R. (1968) Mechanism of enhancement of eccrine sweating by localized heating. J. Appl. Physiol., 25: 255-260.

Miyagawa, T., Ogawa, T., and Asayama, M. (1981) Asymmetry of sweat rate in association with handedness. J. Aichi Med. Univ. Assoc., 9: 243-248 (in Japanese).

OGAwA, T. (1970) Local effect of skin temperature on threshold concentration of sudorific agents. J. Appl. Physiol., 28: 18-22.

Ogawa, T. and Asayama, M. (1978) Frequency of sweat expulsions, as indicator of sudomotor neural activity. In: New Trends in Thermal Physiology, ed. by Houdas, Y. and GuIEU, J. D. Masson. Paris, pp. 105-107.

SARGENT, F., II (1962) Depression of sweating in man: So-called "sweat gland fatigue". In: Advances in Biology of Skin, Vol. 3, Eccrine Sweat Glands and Eccrine Sweating, ed. by Montagna, W., Ellis, R. A., and Silver, A. F. Pergamon Press, Oxford, pp. 163-212. 